\title{
Hierarki Efek Model Pada TAYangan IKLAN Youtube
}

\section{${ }^{1}$ Fenny Afriana, ${ }^{2}$ Agnes Puji Rahayu, ${ }^{3}$ Henny Agustiningrum}

\author{
${ }^{1,2,3}$ Sekolah Tinggi Ilmu Komunikasi InterStudi \\ email: 'veniapr@hotmail.com, 2agneshandayani2016@gmail.com,3hennyagsustiningrum@gmail.com
}

\begin{abstract}
Hierarchy Effect concept according to Belch and Belch is a process that show where Advertising can work. Advertising is influence the consumer through a few stages, starting from first awareness about the product or a service until a real stage within a buying phase. The main reason from this model is that advertising work after an interval of some time, not as instantly. A message from advertising not immediately give an effect to an act but begun with some stages, every each stage must be fulfilled before they are going to the next stage. According to Russell and Lane, ad impressions is a message formed into an audio and visual that tend to being interactive nor noninteractive, to attract audience's attention on a kind of goods and any services with or without a helper tool in a way to awaken the desire of buying any kind of goods or any services. This research using survey method that applied to 61 STIKOM InterStudi's college students on Public Relation Major that in academic year of 2014-2015. Depend of using Pearson Correlation Test that indicate the relation between ad impression and buy interest is amount 0,716 and significant. According to the research's inference we can know that the result from calculation on factor analysis and alpha cronbach showing that ad impressions and buy interest having reliable and fulfilled condition of validity's level.
\end{abstract}

Keywords: Ad Impression, YouTube Advertising, Service Buy Interest, Hierarchy of Effects.

\begin{abstract}
Abstrak. Konsep Hierarki Efek menurut Belch dan Belch menunjukkan proses tempat iklan bekerja. Iklan mempengaruhi konsumen melalui beberapa tahap, dimulai dari kesadaraan pertama mengenai produk atau jasa hingga tahap pembelian yang sesungguhnya. Alasan mendasar dari model ini adalah bahwa iklan bekerja setelah selang beberapa waktu, bukan secara instan. Pesan iklan yang disampaikan tidak langsung mempengaruhi kepada tindakan tetapi didahului dengan beberapa tingkatan sebelumnnya, setiap tingkatan harus terpenuhi sebelum naik ke tingkatan berikutnya. Sedangkan konsep tayangan iklan menurut Russel dan Lane merupakan pesan dalam bentuk suara dan gambar yang bersifat interaktif maupun tidak, dengan atau tanpa alat bantu untuk menarik perhatian masyarakat terhadap suatu jenis barang atau jasa tertentu dengan cara membangkitkan keinginan membeli guna membeli barang atau jasa tersebut. Penelitian ini menggunakan metode survei kepada 61 Mahasiswa STIKOM InterStudi Jurusan Humas Tahun Akademik 20142015. Dengan menggunakan uji korelasi Pearson menyatakan bahwa hubungan antara tayangan iklan dengan minat beli adalah sebesar 0,716 dan signifikan. Berdasarkan kesimpulan penelitian dapat diketahui bahwa hasil perhitungan pada factor analysis dan alpha cronbach menunjukkan bahwa tayangan iklan dan minat beli (jasa) memiliki tingkat validitas yang memenuhi syarat dan reliabel.
\end{abstract}

Kata Kunci: Tayangan Iklan, Iklan YouTube, Minat Beli Jasa, Hierarchy of Effects.

\section{Pendahuluan \\ Model Hierarki Efek digunakan sebagai indikator minat beli}

dikarenakan model ini mencakup tahaptahap proses pengaruh iklan terhadap sikap konsumen. Mulai dari tahap 
kognitif, afektif hingga konatif yang di dalamnya terdapat tahapan yang berurutan mengenai iklan yang mempengaruhi tindakan dari konsumen (Belch \& Belch, 2009).

Menurut (Jefkins, 1995) iklan merupakan bentuk kegiatan komunikasi non personal yang disampaikan lewat media dengan membayar ruang yang dipakainya untuk menyampaikan pesan yang bersifat membujuk (persuasif) kepada konsumen oleh perusahaan, lembaga non-komersial, maupun pribadi yang berkepentingan. Tayangan iklan merupakan pesan dalam bentuk suara dan gambar yang bersifat interaktif maupun tidak, dengan atau tanpa alat bantu untuk menarik perhatian masyarakat terhadap suatu jenis barang atau jasa tertentu dengan cara membangkitkan keinginan membeli guna membeli barang atau jasa tersebut (Russell \& Lane, 2007)

Kini media terbagi menjadi dua jenis yakni, media tradisional dan media digital. Media tradisional mengacu kepada cara konvensional media massa seperti seperti tv, radio, koran, majalah dan media cetak lainnya. Sedangkan, media digital mengacu kepada berbagai bentuk dan perkembangan terus menerus dari alat komunikasi, dari websites, intranets dan alat media sosial, mobile communication, smartphones dan apps. Namun, dari waktu ke waktu kini lebih banyak orang menghabiskan waktunya pada media online dibandingkan media tradisional. Beralihnya konsumsi media yang terjadi pada konsumen ke media digital mejadikan perusahaan untuk berinvestasi lebih pada iklan digital, khususnya online video (Harita, 2015).

Iklan pada media sosial yang menjadi salah satu bagian dari media online, yaitu YouTube. Untuk satu tayangan iklan jumlah penonton iklan mencapai angka yang cukup tinggi, sebesar 2.047.754 penonton (Grab
Indonesia, 2016) Berdasarkan teori tayangan iklan (Russell \& Lane, 2007) serta teori minat beli (Assael, 1998) dapat disimpulkan bahwa tayangan iklan dan minat beli (jasa) memiliki tingkat validitas yang memenuhi syarat dan reliabel.

Penelitan ini mengungkapkan tentang tayangan iklan dan minat beli berdasarkan penelitian terdahulu bahwa memang antara tayangan iklan dengan minat beli saling memiliki keterikatan (Caesaria, 2016). Berdasarkan observasi umum dan data yang diperoleh bahwa objek penelitian memiliki karakteristik yang sangat sesuai dengan pengguna internet terbanyak di Indonesia. Serta telah didapatkannya data dari hasil penyebaran kuesioner kepada beberapa mahasiswa, diketahui bahwa mahasiswa STIKOM InterStudi Jurusan Humas Tahun Akademik 2014-2015 (STIKOM InterStudi, 2016) banyak yang menggunakan aplikasi jasa transportasi GrabBike. Mengingat bahwa kehadiran internet beriringan dengan kelahiran kelompok usia muda (antara 18-24 tahun). Pengguna YouTube sebagian besar adalah kaum muda dengan usia 13-24 tahun. Gambaran pengguna YouTube secara umum sebagai berikut: Usia terbanyak adalah mereka yang berusia diantara 18-24 tahun, disusul usia 25-34 dan usia 13-17 tahun. Asosiasi Penyelenggara Jasa Internet Indonesia (APJII) menyatakan bahwa pengguna internet terbanyak di Indonesia ialah mereka yang berkisar di usia 18-24 tahun. Sesuai data yang diperoleh dari APJII, maka dapat disimpulkan bahwa pengguna internet terbanyak di Indonesia ialah remaja dan pekerja (Lihat Detail Statistik, 2017)

\section{Kerangka Teori}

Tayangan iklan merupakan pesan dalam bentuk suara dan gambar yang bersifat interaktif maupun tidak, dengan atau tanpa alat bantu untuk 
menarik perhatian masyarakat terhadap suatu jenis barang atau jasa tertentu dengan cara membangkitkan keinginan membeli guna membeli barang atau jasa tersebut (Russell \& Lane, 2007). Sedangkan menurut Wells pada tayangan iklan terdapat 5 dimensi di dalamnya, yakni video (gambar), audio (suara), talent (bintang iklan), prop (produk), pacing (langkah-langkah dalam mengukur). Definisi dari dimensi Video (Gambar) mengandung rangkaian adegan yang berupa gerakan kata-kata yang menceritakan sesuatu. Video berperan penting untuk memberikan informasi kepada khalayak karena itu di dalam adegan video harus mencerminkan karakteristik yang dapat dikenal oleh khalayak. Sedangkan pada tayangan iklan merupakan audio-visual sehingga elemen audio (Suara) ini menjadi penting. Tanpa elemen audio ini, penginformasian sesuatu menjadi kurang menarik. Dalam tayangan iklan pesan dituangkan dalam bentuk lisan atau verbal berupa kata-kata. Diantaranya Talent (Bintang Iklan). Pada iklan audio-visual dalam tayangan iklan yang selain menggunakkan katakata juga menggunakkan cerita atau gambar agar semakin menarik. Untuk itu, tayangan iklan membutuhkan seseorang untuk memerankan adegan yang terdapat dalam iklan yang menunjukkan manfaat, cara kerja, kehebatan dan lain sebagainya agar khalayak mendapat informasi yang cukup. Selain itu prop (Produk). Hal yang penting dalam sebuah iklan adalah produk yang diiklankan. Adegan, cerita, figur, musik, dan lainnya yang digunakan hanyalah sebagai pendukung dalam menunjukkan keungulan produk. Serta pacing (Langkah-langkah dalam mengukur) Setiap khalayak mempunyai daya tangkap yang berbeda-beda. Karena itu, pengiklan harus dapat meranang iklannya sedemikian rupa agar iklan itu mudah untuk dimengerti dan ditangkap maknanya dengan baik oleh khalayak. Pacing adalah bagian keseluruhan pengakhiran pesan (Wells, 1997).

YouTube adalah suatu situs web video sharing (berbagi video) yang hadir dalam dunia maya atau digital internet. Diciptakan atau dibuat oleh 3 orang pekerja PayPal, YouTube: Chad Hurley, Steve Chen, and Jawed Karim, pada Februari 2005 (USA TODAY online, 10/11/2006). Melalui YouTube, pengunjung internet atau situs ini bisa meng-upload, melihat atau berbagi video. (Fadhal \& Nurhajati, 2012). Berikut ini penjelasan jenis-jenis iklan yang dapat tampil dengan konten video di YouTube. Pertama adalah Display Ads (Iklan Bergambar) Iklan muncul di sebelah kanan video dan di atas daftar saran video. Kedua terdapat Overlay Ads (Iklan Berlapis) Iklan ini bentuknya seperti CPC yang ada di dalam blog, iklan overlays (hamparan) semi transparan yang muncul di $20 \%$ bagian bawah video. Apabila penonton video meng-klik iklan jenis overlays ads ini, maka orang yang meng-upload video tersebut mendapatkan penghasilan dari hasil klik yang dilakukan penonton tadi. Ketiga ialah Skippable Video Ads (Iklan Video yang dapat Dilewati). Iklan video yang dapat diabaikan atau dilewati adalah iklan yang dapat diabaikan pemirsa setelah 5 detik, jika mau. Disisipkan sebelum, selama, atau setelah video utama. Keempat NonSkippable Video Ads (Iklan Tidak Bisa Dilewati) Iklan video yang tidak dapat diabaikan atau dilewati harus ditonton sebelum video Anda dapat ditonton. Iklan video panjang yang tidak dapat diabaikan dapat berdurasi hingga 30 detik. Iklan ini bisa muncul sebelum, selama, atau setelah video utama. Kemudian yang kelima terdapat Bumper Ads (Iklan Bumper) Iklan video yang 
tidak dapat dilewati berdurasi hingga 6 detik yang harus ditonton sebelum video Anda dapat dilihat. Terakhir adalah Sponsored Cards (Kartu Bersponsor) Kartu bersponsor menampilkan konten yang mungkin relevan dengan video yang sedang ditonton, contohnya seperti produk yang ditampilkan di video. Konsumen akan melihat promosi untuk kartu tersebut selama beberapa detik, mereka juga dapat mengeklik ikon di sudut kanan atas video untuk menjelajahi kartu (YouTube, 2017)

Model Hierarki Efek digunakan sebagai indikator minat beli dikarenakan model ini mencakup tahaptahap proses pengaruh iklan terhadap sikap konsumen. Mulai dari tahap kognitif, afektif hingga konatif yang di dalamnya terdapat tahapan yang berurutan mengenai iklan yang mempengaruhi tindakan dari konsumen. Pada tahap kognitif terdapat tahap awareness (kesadaraan) serta knowledge (pengetahuan). Untuk tahap afektif terdapat tahap liking (menyukai), preferences (kecenderungan), conviction (keyakinan). Yang terakhir adalah tahap konatif yakni tahap purchase (pembelian). Namun, sebagai indikator minat beli peneliti hanya menggunakan dua tahap yaitu tahap kognitif hingga tahap afektif. Hal ini dikarenakan minat beli tidak mencapai tahap konatif yaitu tahap purchase (pembelian). Tahap Kognitif meliputi beberapa tahap yaitu: Awareness (Kesadaran) Kesadaran berarti bahwa pesan yang telah dibuat menimbulkan kesan kepada pembaca atau penonton yang kemudian dapat membantu mengidentifikasikan pesan. Perlu diperhatikan walaupun kesadaran akan iklan datang terlebih dahulu tapi itu bukanlah tujuan terutama dari iklan. Yang menjadi pokok utama dari iklan adalah kesadaran merek, produk, atau jasa yang ditawarkan. Selanjutnya
Knowledge (Pengetahuan) Knowledge adalah pengetahuan, yang dimaksudkan pengetahuan disini adalah dimana konsumen memahami dan mengetahui fungsi dan karakteristik dari sebuah produk. Pada tahap ini khalayak telah sadar akan sebuah produk tetapi masih membutuhkan informasi tentang manfaat dari produk tersebut. Berkaitan dengan perasaan manusia terhadap suatu produk baik positif atau negatif. Aspek affective meliputi tiga tahap yaitu liking (suka), preference (memilih), dan conviction (yakin). Pertama ialah Liking (Menyukai) pada tahap ini khalayak telah memutuskan menyukai atau tidak menyukai produk. Kesukaan konsumen terhadap suatu produk sangat dipengaruhi keadaan diri konsumen menyangkut konsumsi produk, pengalaman belajar dan loyalitas merek. Kedua adalah tahap Preference (Kecenderungan) Preference yaitu sebuah pilihan konsumen terhadap suatu jenis produk dibandingkan dengan produk sejenis lainnya (kompetitor) atau yang biasa disebut perbandingan brand. Biasanya dihasilkan dari pengalaman konsumen yang menggunakan suatu brand tertentu. Jika menghasilkan ketidakpuasaan pada brand tersebut maka konsumen akan mengganti dengan produk lain. Terakhir conviction (Keyakinan) adalah suatu kepercayaan yang kuat yang telah tertanam di dalam perilaku seseorang. Pendapat berdasarkan conviction (keyakinan) sangat sulit untuk diubah, jadi pengiklan yang mampu membangun conviction (keyakinan) pada target audiensnya mendapatkan keunggulan kompetitif yang kuat. Tahap terakhir yakni tahap konatif terdapat tahap Purchase (Pembelian). Tahap ini terjadinya transaksi jual-beli purchase (pembelian). Disini khalayak memutuskan akan membeli atau tidak produk yang diiklankan (Wells, 1997). 


\section{Metodologi}

Pada penelitian ini menggunakan pendekatan secara kuantitatif, menurut (Kriyantono, 2006) penelitian kuantitatif tidak terlalu mementingkan aspek keluasan data sehingga data hasil riset dianggap merupakan representasi dari seluruh populasi. Dapat terlihat dari penelitian sebelumnya, mengapa penelitian ini menggunakan pendekatan kuantitatif dikarenakan pengunaan model hierarki efek sesuai dengan pendekatan penelitian secara kuantitatif. (Caesaria, 2016). Sedangkan pemilihan metode penelitian pada penelitian ini adalah menggunakan metode survei. Menurut (Umar, 2004) penelitian survei merupakan salah satu bagian dari pendekatan penelitian kuantitatif. Kemudian teknik pengumpulan data yang diaplikasikan guna memperoleh data-data pada penelitian ini adalah dengan cara melakukan survei melalui kuesioner terhadap responden yang telah ditentukan (Bungin, 2010). Kuesioner yang digunakan dalam penelitian ini adalah kuesioner pertanyaan tertutup. Mengacu pada penelitian sebelumnya, menurut (Caesaria, 2016) penelitian yang mengunakan model hierarki efek sesuai untuk mengunakan teknik pengumpulan data menggunakan kuesioner pertanyaan tertutup. Sampel yang digunakan porsinya cukup mewakili populasi yaitu 159 (STIKOM InterStudi, 2016) dan setelah menggunakan rumus perhitungan sampel Taro Yamane (Hamidi, 2010) dapat ditarik jumlah sampel sebesar 61 sampel. Maka dapat diyakinkan bahwa generalisasi yang diambil menggambarkan populasi, sehingga penemuan dan kesimpulan yang diperoleh dari sampling tersebut adalah sah atau valid.

\section{Hasil dan Diskusi}

Dari hasil kesimpulan yang ada dapat terlihat bahwa nilai kekuatan yang terbentuk antara Tayangan Iklan dan Minat Beli adalah sebesar 0,716. Bila mengacu pada interval korelasi maka dapat diartikan nilai tersebut adalah merupakan nilai yang kuat serta memiliki hubungan yang signifikan. Nilai tersebut juga mengartikan $\mathrm{P} \neq 0$ atau menolak hipotesis nol (Ho) dan menerima hipotesis alternatif $(\mathrm{Ha})$ (Sugiyono, 2006).

\section{Kesimpulan}

Tayangan iklan memiliki nilai dengan tingkat yang kuat serta signifikan dengan minat beli. Sehingga tayangan iklan memang mempengaruhi kecenderungan konsumen untuk membeli suatu merek atau mengambil tindakan yang berhubungan dengan pembelian yang diukur dengan tingkat kemungkinan konsumen melakukan pembelian (Assael, 1998)

\section{Daftar Pustaka}

Assael, H. 1998. Consumer Behavior and Marketing Action 6th edition. New York: International Thomson Publishing.

Belch, George dan Michael E. Belch. 2009. Advertising and Promotion: An Intergrated Marketing Communication Perspective. 8th edition. New York: McGraw Hill.

Bungin, Burhan. 2010. Metodologi Penelitian Kuantitatif: Komunikasi, Ekonomi, dan Kebijakan Publik Serta Ilmu-ilmu Sosial Lainnya. Edisi pertama. Jakarta: Kencana.

Hamidi. 2010. Metode Penelitian dan Teori Komunikasi. Malang: UMM. Jefkins, Frank. 1995. Periklanan Edisi Ketiga. Jakarta: Erlangga. 
Kriyantono, Rachmat. 2006. Teknik Praktis Riset Komunikasi. Jakarta: Kencana.

Russell, J. Thomas dan W. Ronald Lane. 2007. Kleppner's Advertising Procedure first book. Jakarta: PT Elex Media Komputindo.

Sugiyono. 2006. Metode Penelitian Kuantitatif Kualitatif dan $R \& D$. Bandung: Alfabet CV.

Umar, Husein. 2004. Metode Penelitian untuk Skripsi dan Tesis Bisnis. Cat ke 6. Jakarta: PT Raja Grafindo Persada.

Wells, William dkk. 1997. Advertising Principles and Practice. New Jersey: McGraw-Hill.

\section{Data}

Bantuan YouTube. "Format Periklanan Youtube".

(https://support.google.com/youtube /answer $/ 2467968 ? \mathrm{hl}=\mathrm{id}$ ). 21 Maret 2017, 10:35 WIB.

Grab Official. "Selalu \#PilihAman" (https://www.youtube.com/watch?v =POA6q ZurTL8). 17 Februari 2017, 21:40 WIB.

Kominfo. "Lihat Detail Statistik". (http://statistik.kominfo.go.id /site/ data? idtree $=\quad 424 \&$ iddoc $=1321 \&$ data-data_page $=3$ ). 18 November 2016, 23:12 WIB.

\section{Jurnal}

Fadhal, Soraya dan Lestari Nurhajati. 2012. Identifikasi Identitas Kaum Muda di Tengah Media Digital (Studi Aktivitas Kaum Muda Indonesia di Youtube). Jakarta.

Harita, Gesti Rizky Salasi. 2015. Pengaruh Sikap Konsumen pada Online Video Advertising "Nikmati Oreo Sesukamu” pada Situs Youtube terhadap Keputusan Pembelian. Bogor.

Universitas Pertahanan, 2015, Dynamic of Terrorism: Terror Crime Nexus, Prodi Asymmetric Warfare. 